\title{
Fetal Hemoglobin Level as Indicator of Frequency and Duration of Blood Donation
}

\author{
Ogbodo Sylvester Ogbonna $^{1 *}$; Chukwurah Ejike Felix ${ }^{2}$; Eze Chukwuka Wencelaus ${ }^{1}$; Eze Richard \\ Ikechukwu $^{3}$; Udengwu Nonyerem Lilian ${ }^{4}$ \\ ${ }^{1}$ Dept. of Medical Biochemistry, Faculty of Basic Medical Sciences, College of Medicine, Enugu \\ State University of Science \& Technology, Enugu, Nigeria. \\ ${ }^{2}$ Dept. of Hematology/Immunology, Faculty of Clinical Medicine, College of Health Sciences, \\ Ebonyi State University, Abakaliki, Nigeria. \\ ${ }^{3}$ Dept. of Medical Laboratory Science, Madonna University, Elele, Rivers State, Nigeria. \\ ${ }^{4}$ Dept. of Hematology/Immunology, School of Medical Laboratory Sciences, University of Nigeria \\ Teaching Hospital, Enugu, Nigeria.
}

\begin{abstract}
Hemoglobin $\mathrm{F}$ is normal hemoglobin seen in minute amount in adults. Increase in its level in adults is an indication of erythropoietic stress, which in most cases is linked to hemoglobinopathy. This study was undertaken to assess if physiological erythropoietic stress, as seen in commercial blood donation, can increase it and thus be used as an indicator of frequency and duration of blood donation. The study involved 152 subjects including 88 commercial blood donors and 64 controls. Hemoglobin $\mathrm{F}$ was expressed as percentage concentration of the total hemoglobin. Results showed that hemoglobin $\mathrm{F}$ significantly increased in commercial blood donors when compared with the controls. There was also strong positive correlation between hemoglobin $\mathrm{F}$ level and age of the donors which was not the case with the controls. The results indicate that hemoglobin F level can be used as an indicator of the frequency and duration of blood donation. Though blood donation has some health benefits, the disadvantages of frequent donation outweigh these benefits and should be discouraged.
\end{abstract}

Key words: Hemoglobin F; Indicator; Frequency; Blood donation

\section{Introduction}

Fetal hemoglobin $(\mathrm{HbF})$, which is not abnormal hemoglobin, is the major hemoglobin in fetal blood. It comprises about $85 \%$ of fetal blood at birth (Steinberg et al, 2014). Though the concentration usually declines during the first two to three months of life, traces of it are still found as old as two years and beyond. However, appreciable concentrations can be found in adults with certain disorders of erythropoietic organs like in pernicious anemia, sickle cell disease, thalassemia and juvenile chronic myelomonocytic leukemia (Rochette et al, 1994; Rees et al, 1999). The persistence of HbF level to adult age is not generally associated with clinical symptoms and its presence in good percentage is a good modulating factor when present with hemoglobinopathies. The modulating property is conferred on it by its resistance to denaturation with alkali and its higher affinity for oxygen when compared to adult hemoglobin (HbA). Its high affinity for oxygen makes it possible for more oxygen in the system as percentage concentration of $\mathrm{HbF}$ increases, making it a stabilization factor in hemoglobinopathies, especially sickle cell disease (Akinsheye et al, 2011). Furthermore, this high affinity for oxygen coupled with greater ease to release carbon dioxide makes $\mathrm{HbF}$ an instrument for compensatory mechanism to overcome complications that would have arisen from anoxemia. Under physiological conditions, the presence of small concentration of $\mathrm{HbF}$ in all cells inhibits sickling of red cells thereby preventing disease manifestation. Unfortunately, a comparable amount of it in sickle cell anemia is confined to a few red cells (normal red cells) and therefore 
cannot prevent sickling. Presently, measurement of $\mathrm{HbF}$ level in adults is used as diagnostic tool in few cases: (a) detection of fetal cells in maternal circulation as an important support for the clinical diagnosis of feto-maternal hemorrhage - a potentially life-threatening obstetric complication, (b) persistence of high level in blood as an assistance in the diagnosis of hemoglobinopathies, especially sickle cell disease and (c) its increase in blood as assistance in evaluating recovery from hematopoietic cells transplantation (Trent, 2005; Solomonia et al, 2012).

Physiologically, $\mathrm{HbF}$ is of great advantage to normal developing fetus. This is because at this condition, $\mathrm{HbF}$ has low affinity for 2,3-diphosphoglycerate. This low affinity confers on it the higher binding capacity for oxygen, which is of great advantage to the fetus to withstand or resist anoxemia and avoid carbon dioxide toxicity. In adult, high level of $\mathrm{HbF}$ in blood has been linked to hemopoietic stress like hemolysis or profuse bleeding, as well as other causes of constant blood loss. The best described intentional frequent blood loss is through commercial blood donation. In voluntary blood donation, donors are restricted to three to four donations per year. This is because it takes adult males about 12 weeks and adult female 16 weeks to replace a pint of blood given out. However, commercial blood donors tend to donate as many times as they can access the service per year due to its paltry financial return. Such donors are usually touts who have little or no other means of livelihood; instead, they rely on the financial returns from the donation to meet most of their financial needs. Commercial blood donation may account for $60-80 \%$ of blood needed for transfusion in developing countries, especially those with distressed economies. It is worthy to note that in these distressed economies, governments are not in control of blood transfusion services. This is because most of them have not established Blood Transfusion Centers (BTC) and where such exists, it will be left in the wrong hands (political friends or non-professionals) to manage/administer. Thus, maladministration and rush to gain from the appointment leave such centers non-functional, or at best barely functional that they cannot meet the purpose for which they were established. Thus, stand-alone laboratories capitalize on this to create small or makeshift blood banks. With this situation, commercial blood donors move from one blood bank to another to donate as frequently as they want without being spotted. After each donation, they are given multivitamin tablets to be taken for some days to enhance erythropoeisis. The multivitamin gesture, which increases erythropoeisis, will encourage the donors to come back or move to another laboratory for another donation earlier than necessary. The need to track such donors and dissuade them from making frequent donations cannot be overemphasized. However, there is dearth of methods for the identification of these multiple blood donors, except those that can be physically identified. It is possible that frequent blood donation can induce hemopoietic stress in such donors, prompting increase in the concentration of $\mathrm{HbF}$ in the donor. If this is true, then the level of $\mathrm{HbF}$ in blood donors, who have no other possible cause of the increase, can be used as an indicator of how frequent or long the individual has donated blood. We report the determination of percentage concentrations of $\mathrm{HbF}$ in commercial blood donors in Enugu State of Southeast Nigeria with a view to using the $\mathrm{HbF}$ level to predict how frequent and/or long one has donated blood.

\section{Materials and Methods}

Ethical clearance: This is a cross-sectional study done between January and June, 2017. It involved commercial blood donors within the Enugu metropolis in Enugu State of Southeast Nigeria. The ethical clearance for this study was obtained from Medical Research Ethics Committee of University of Nigeria Teaching Hospital, Ituku-Ozalla, Enugu, Nigeria.

Subjects: A total of 152 subjects aged between 20 and 50years were recruited for the study. This comprised of 88 donors and 64 controls. These control subjects were age-matched apparently healthy students and workers of the teaching hospital who have never donated blood or have not done so in six months prior to the study.

Sample collection: A total of $3.0 \mathrm{ml}$ of venous blood were collected from each subject into a sequestered container and washed three times using normal saline (9\% sodium chloride in water). The packed cells were then subsequently lysed using equal volumes of water and carbon tetrachloride. The lysed cells were vigorously shaken for a minute and then centrifuged at $3000 \mathrm{rpm}$ for 30 minutes. The clear supernatant was then transferred to a clean test tube for use. Samples were collected and processed in batches of 5 to 10 for easy handling. 
Laboratory analysis: Method used for the determination of the percentage concentration of HbF was as earlier reported by Wild and Bain (2006).

Statistical analysis: Graph Pad Prism 5.3 version was used to calculate differences in means and correlation with age. Statistical significance was taken to be $\mathrm{p}<0.05$.

\section{Results}

The results from this study showed that commercial blood donors have mean hemoglobin F level of $0.49 \pm$ $0.04 \%$ of the total hemoglobin. This was statistically higher $(\mathrm{p}<0.001)$ than that of non-donors (controls) who have mean hemoglobin $F$ level of $0.16 \pm 0.01 \%$. Figure 1 is a comparative study of the mean percentage hemoglobin $\mathrm{F}$ in commercial donors and non-donors (controls) according to age. The results from commercial blood donors at different age group were $0.39 \pm 0.03 \%$ for 20 - 30years, $0.54 \pm 0.06 \%$ for $31-40 y e a r s$ and $0.66 \pm 0.13 \%$ for $41-50$ years, while results from controls were $0.18 \pm 0.02 \%$ for $20-$ 30years, $0.16 \pm 0.01 \%$ for $31-40$ years and $0.15 \pm 0.02 \%$ for $41-50$ years, showing that HbF levels increased significantly in donors at all the age groups when compared with non-donors at the corresponding age groups.

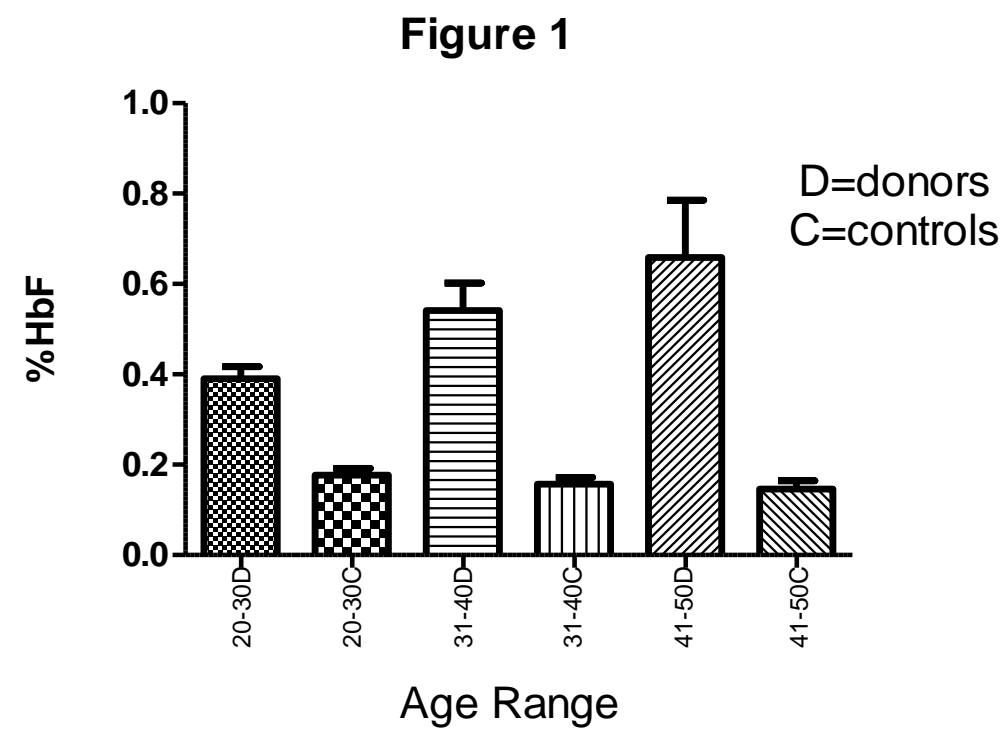

Figure 1: Hemoglobin $F$ in donors and non-donors at different age group

Figure 2 is a correlation between age groups of the commercial blood donors and percentage hemoglobin F. The results were $0.39+0.03 \%$ for $20-30$ years, $0.54+0.06 \%$ for $31-40$ years and $0.66+0.12 \%$ for $41-$ 50years, indicating that there was positive correlation between hemoglobin $\mathrm{F}$ level and ages of commercial blood donors $\left(\mathrm{p}=0.010 ; \mathrm{R}^{2}=0.102\right)$. This implies that the older the donor the more percentage of the hemoglobin. 
Figure 2

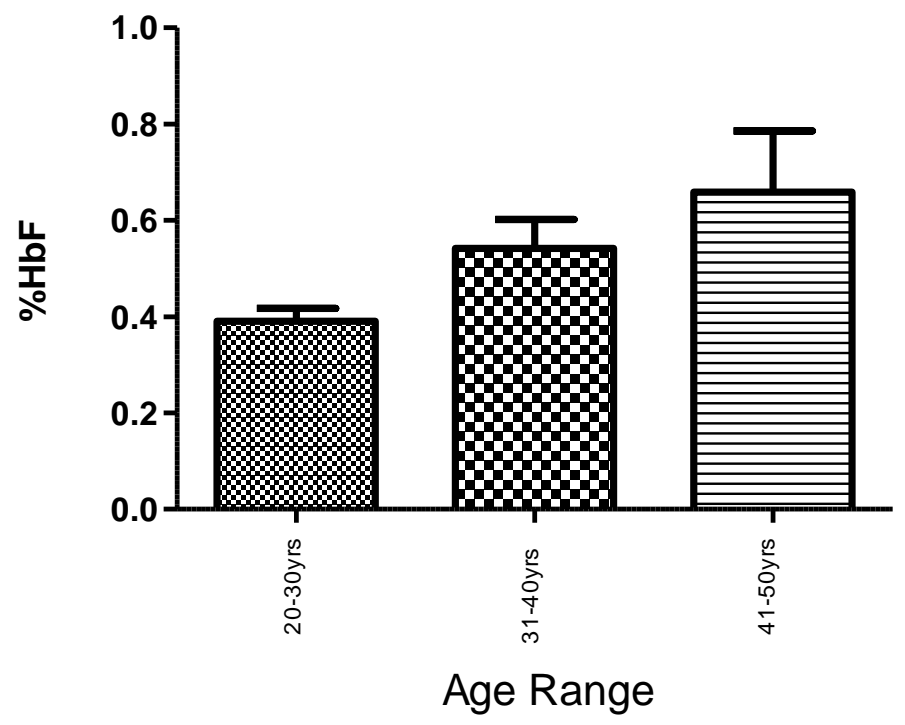

Figure 2: Correlation between percentage hemoglobin $F$ and age groups of donors

Figure 3 shows correlation between the percentage hemoglobin $\mathrm{F}$ and age groups in non-donors (controls). The results were $0.18+0.02 \%$ for $20-30$ years, $0.16+0.01 \%$ for $31-40$ years and $0.15+0.02 \%$ for $41-$ 50years. Though there was continued decrease of hemoglobin $\mathrm{F}$ as age increased but the correlation was not statistically significant $\left(\mathrm{p}=0.433 ; \mathrm{R}^{2}=0.027\right.$ ), implying that hemoglobin $\mathrm{F}$ level does not change appreciably in apparently healthy adults.

Figure 3

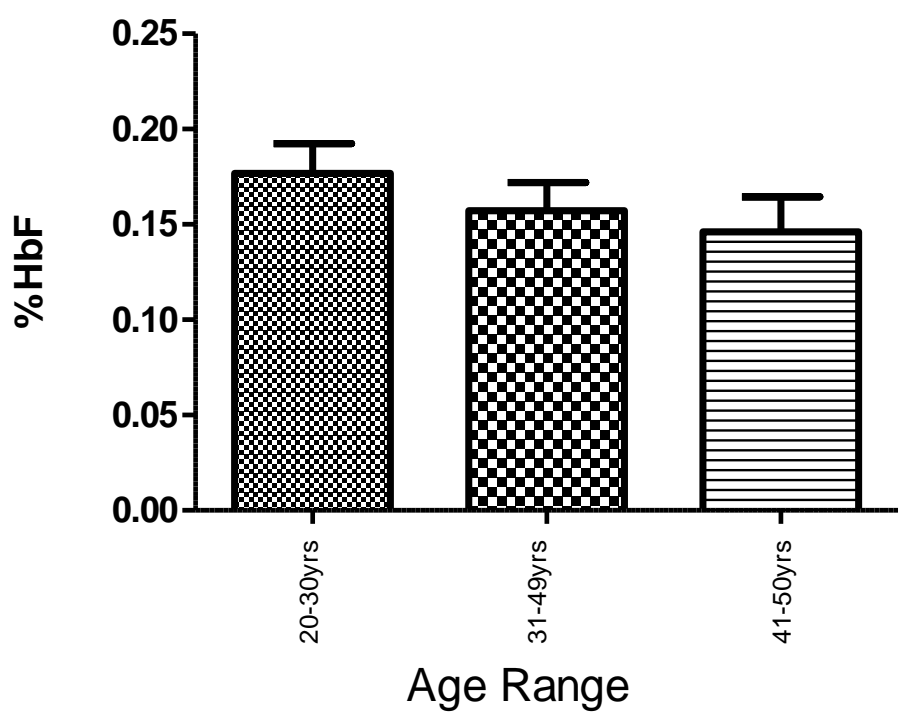

Figure 3: Correlation between percentage hemoglobin $F$ and age groups of controls

\section{Discussion}

The results of this study showed that HbF levels increased significantly $(\mathrm{p}<0.001)$ in commercial blood donors when compared with the levels in non-donors (controls). On formation, the hemoglobin found in fetuses is termed embryonic hemoglobin which usually switches over to fetal hemoglobin within the first few weeks of life, approximately 10 to 12 weeks of life. This may account for observed increase in percentage $\mathrm{HbF}$ in adult females during pregnancy (Italia et al, 2007; Dana and Fibach, 2018). However, 
after six months of life, the synthesis of adult hemoglobin (HbA) is fully activated and this lasts till death. As this scenario occurs under physiological condition, there is continuous decline in concentration or level of the preceding form of hemoglobin such that at adult life, fetal hemoglobin level becomes negligible (about $0.1 \%$ of hemoglobin concentration). An exception is in hereditary persistence of fetal hemoglobin seen in certain genetic abnormalities. Therefore, any time significant level of $\mathrm{HbF}$ is found in apparently healthy non-pregnant adult, it should be attributed to erythropoietic stress. Thus, the finding of significantly increased $\mathrm{HbF}$ levels in this study among apparently healthy blood donors is an indication of increased erythropoietic stress from frequent blood donation. $\mathrm{HbF}$ is formed by $\alpha_{2} \gamma_{2}$ globin chains while $\mathrm{HbA}$ is formed by $\alpha_{2} \beta_{2}$ globin chains, hence, the major difference between the two is the predominant expression of $\gamma$-globin genes in $\mathrm{HbF}$ and $\beta$-globin genes in $\mathrm{HbA}$ (Stamatoyannopoulos, 2005). The $\gamma$-globin subunit is the feature that allows $\mathrm{HbF}$ to bind more strongly to oxygen than any other subunit. Therefore, it is possible that frequent blood donation which is seen to cause increase in $\mathrm{HbF}$ level, from this study, does so by increasing the expression of $\gamma$-globin genes against any other gene involved in erythropoiesis. By extension, the same gene may account for the ability of the commercial donors to recover easily and fairly well, affording them the opportunity to donate several times per year with little or no observable health shortcoming. The mechanism may be related to that of increased expression of $\gamma$-globin genes in adults with hemoglobinopathies, like sickle cell anemia, and which help them to compensate for the defective $\beta$-globin products and significantly reduce the symptoms of such hemoglobinopathy (Xu et al, 2009). It may also be related to increase in erythropoietin levels, leading to bone marrow expansion as seen in beta thalassemia syndromes (Rees et al, 1999). Physiologically, it has been demonstrated that donation of whole blood, though reduces hemoglobin mass (about $7 \%$ in a day and 5\% a week after), increases serum erythropoietin (Meurrens et al, 2016). Furthermore, it has earlier be demonstrated that induced increase in $\gamma$-chain production has beneficial effects, particularly, increasing the synthesis of total hemoglobin (Galanello and Cao, 1998). Therefore, for these commercial blood donors to meet donation criteria, especially hemoglobin level, increase in expression of $\gamma$-globlin gene, as well as erythropoietin, is a possibility. By this mechanism, those with more donations will have higher $\mathrm{HbF}$ levels, making $\mathrm{HbF}$ level an indicator of how frequent or long one has donated blood.

The results of this study also showed that HbF levels in commercial donors increased significantly as the age of the donors increased, showing strong positive correlation between age and $\mathrm{HbF}$ level under erythropoietic stress. This finding is in disagreement with known physiological norm which posit that HbF level decreases as age increases (Rochette et al, 1994). Moreover, the results from the controls showed that HbF levels decreased as age increased. Though the correlation in controls was not statistically significant, it is a confirmation that significant correlation obtained from commercial donors was as a result of erythropoietic stress, implying that the older donors have donated blood more than the younger ones. Occasional or well spaced blood donation has been postulated to have some advantages including reduced risk of obesity, cancer, hemochromatosis, liver and pancreas damages and improved cardiovascular and general health (BMRS, 2018). However, frequent and long term blood donations without giving enough time for cell recovery will likely have damaging effects. Long term adverse effects of frequent blood donation like refractoriness of the bone marrow cells, which leads to anemia and anemic heart failure, may be the same features seen in some cancer cases where increased $\mathrm{HbF}$ levels were also observed (Rautonen and Siimes, 1990; Wolk et al, 2006; Wolk et al, 2007; Wolk and Martin, 2012). Moreover, short term adverse effects like bruising, continuous bleeding, dizziness, lightheadedness and nausea, pain and physical weakness are constant experience, some of which are experienced even with first time donors. Pathetically, the paltry financial returns realizable from this practice make these commercial blood donors to overlook and hide these obvious adverse effects, as well as lazy and unable to struggle for other means of livelihood. Therefore, insisting on good spacing between one donation and another will not only ensure the derivable health advantages but will also help to avoid these adverse effects and encourage the donors to seek other means of providing for themselves. In addition, the practice will give ample time for the erythropoietic cells to recover fully from each stress, affording the donor the opportunity of giving rich blood unit each time.

\section{Conclusion}

The results of this study showed that $\mathrm{HbF}$ level increased significantly as number of blood donation increased. This implies that $\mathrm{HbF}$ level can be used as an indicator of frequency of blood donation especially 
by commercial blood donors. Considering the benefits of presence or increased level of $\mathrm{HbF}$ in individuals, the results seem to encourage unlimited number of blood donation per donor per year. However, one cannot forget easily the consequences of such action, which outweighs the advantages. Governments are advised to take full control of Blood Transfusion Centers, appoint qualified personnel to manage them and find a way of identifying donors to avoid multiple donations.

\section{References}

1. Akinsheye I, Alsultan A, Solovieff N, Ngo D, Baldwin CT, Sebastiani P, Chui DHK, Steinberg MH (2011). Fetal hemoglobin in sickle cell anemia. Blood 118(1): 19-27. DOI: 10.1182/blood-2011-03325258.

2. Benefits and Risk Management Services (BRMS) (2018). Health Benefits of Donating Blood. (https://www.brmsonline.com/blog/wellness/healthcare/2018/benefits-of-blood-donation accessed accessed 27/8/2020).

3. Dana M, Fibach E (2018). Fetal hemoglobin in the maternal circulation - contribution of fetal red blood cells. Hemoglobin 42 (2): 138-140.

DOI: $10.1080 / 03630269.2018 .1466712$

4. Galanello R, Cao A (1998). Relationship between genotype and phenotype. Thalassemia intermedia. Annals of New York Academy of Science 850: 325-33. DOI: 10.1111/j.1749-6632.1998.tb10489.x

5. Italia KY, Colah R, Mohanty D (2007). Evaluation of F cells in sickle cell disorders by flow cytometry - comparison with the Kleihauer-Betke's slide method. International Journal of Laboratory Hematology 29 (6): 409-14. DOI: 10.1111/j.1365-2257.2006.00884.x

6. Meurrens J, Steiner T, Ponette J, Jabsen HA, Ramaekers M, Wehrlin JP, Vandekerhove P, DeldicqueL (2016). Effect of repeated whole blood donations on aerobic capacity and hemoglobin mass in moderately trained male subjects: a randomized controlled trial. Sports Medicine Open 2(1): 43. DOI: $10.1186 / \mathrm{s} 40798-016-0067-7$

7. Rautonen J, Siimes MA (1990). Initial blood fetal hemoglobin concentration is elevated and is associated with prognosis in children with acute lymphoid or myeloid leukemia. Blut 61 (1): 17-20. DOI: $10.1007 / \mathrm{BF} 1739428$

8. Rees DC, Porter JB, Clegg JB, Weatherall DJ (1999). Why are hemoglobin F levels increased in HbE/beta thalassemia? Blood 94(9): 3199-3204. PMID: 10556208

9. Rochette J, Craig JE, Thein SL (1994). Fetal hemoglobin levels in adults. Blood Reviews 8(4): $213-$ 224. DOI: $10.1016 / 0268-960 x(94) 90109-0$

10. Solomonia N, Playforth K, Reynolds EW (2012). Fetal-maternal hemorrhage: A case and literature review. American Journal of Perinatology Reports 2(1): 7-14. DOI: 10.1055/s-0031-1296028

11. Stamatoyannopoulos G (2005). Control of globin gene expression during development and erythroid differentiation. Experimental Hematology 33(3): 259-271. DOI: 10.1016/j.exphem.2004.11.007

12. Steinberg MH, Chui DHK, Dover GJ, Sebastiani P, Alsultan A (2014). Fetal hemoglobin in sickle cell anemia: a glass half full? Blood 123(4): 481-485. DOI: 10.1182/blood-2013-09-528067

13. Trent RJA (2005). Diagnosis of the haemoglobinopathies. The Clinical Biochemist Reviews 27(1): 27-38. PMID: 16886045.

14. Wild B, Bain BJ (2006). Investigation of abnormal haemoglobins and thalassaemia. In: Dacie and Lewis Practical Hematology. $10^{\text {th }}$ edition, Churchill Livingstone. pp271-310. https://doi/org/10/1016/BO-44-306660-4/50016-7.

15. Wolk M, Martin JE (2012). Fetal haemopoiesis marking low-grade urinary bladder cancer. British Journal of Cancer 107(3): 477-481. DOI: 10.1038/bjc.2012.268

16. Wolk M, Martin JE, Nowicki M (2007). Foetal haemoglobin-blood cells (F-cells) as a feature of embryonic tumour (blastoma). British Journal of Cancer 97(3): 412-419. DOI: 10.1038/bjc.6603867

17. Wolk M, Martin JE, Reinus C (2006). Development of fetal haemoglobin-blood cells (F cells) within coloretctal tumour tissues. Journal of Clinical Pathology 59(6): 598-602. BOI: 10.1136/jcp.2005.029934

18. Xu XS, Hong X, Wang G (2009). Induction of endogenous $\gamma$-globin gene expression with decoy oligonucleotide targeting Oct-1 transcription factor consensus sequence. Journal of Hematology and Oncology 2(15): 1-11. DOI: 10.1186/1756-8722-2-15. 